\title{
Fostering Digital Start-ups: Structural Model of Entrepreneurial Ecosystems
}

\author{
Erkko Autio \\ Imperial College Business School \\ erkko.autio@imperial.ac.uk
}

\author{
Zhe Cao \\ Imperial College Business School \\ z.cao16@imperial.ac.uk
}

\begin{abstract}
Despite rising scholarly, policy and practical interest in the concept of entrepreneurial ecosystems, much of the research to date has remained descriptive in nature and has not considered the fundamental driver of the phenomenon - digitalization. We theorize that entrepreneurial ecosystems represent a novel, distinctive type of regional cluster that facilitate digital start-ups which leverage digital affordances for disruptive business model innovation. Entrepreneurial ecosystems are distinguished from other forms of regional agglomeration by their relative lack of industry and technology specificity; by their organization around the start-up process, by the way they combine and leverage spatial and digital affordances, and by their shared experiential knowledge base on business model innovation. We build a structural model of entrepreneurial ecosystems that comprises four key elements: ecosystem community, resource dynamic, knowledge spill-over dynamic, and general framework conditions.
\end{abstract}

\section{Introduction}

Entrepreneurial ecosystems are a recent phenomenon that has attracted increasing attention over the past decade from a diverse community of policy makers, practitioners, and academics [1-5]. This concept has been widely used to foster an entrepreneurial economy [6]. The entrepreneurial ecosystem movement has rapidly become global, in parallel with and boosted by the widespread adoption of the Lean Entrepreneurship method [7]. This is both reflected in and facilitated by the global proliferation of associated organizational innovations such as new venture accelerators and coworking spaces [8]. Despite the rapid global diffusion of the phenomenon, however, the existing literature on this topic lacks a coherent theoretical grounding and is

\footnotetext{
${ }^{1}$ With the rapid advances in digitalization, this distinction is gradually getting blurred, as new ventures of all kinds increasingly
}

largely practitioner-oriented. Moreover, the bulk of the research on entrepreneurial ecosystems has failed to recognize arguably the most fundamental driver of the phenomenon - that of digitalization [9].

To address these gaps, we first briefly review literature of entrepreneurial ecosystems. Building on the framework proposed by Autio et al. [2], we propose that entrepreneurial ecosystems specialize in fostering a very specific category of entrepreneurial ventures digital start-ups. We define digital start-ups as new ventures that harness digital affordances for business model innovation ${ }^{1}$. The harnessing of digital affordances allows new ventures to dramatically lower their start-up costs, enabling them to adopt an iterative, experimentation-driven approach to their business model design - an approach that differs drastically from the traditional, linear and planning-oriented approach to new venture creation $[7,10,11]$. It is this iterative and experimentation-driven heuristic that entrepreneurial ecosystems facilitate with their distinctive structural elements such as new venture accelerators, co-working spaces, makerspaces, and venture challenges [2]. We build on this insight in our theoretical model of entrepreneurial ecosystems. Our model distinguishes four distinctive elements of these: the entrepreneurial ecosystem community, resource dynamic, knowledge spill-over dynamic, and general framework conditions. Entrepreneurial ecosystems are, in essence, regional communities of stakeholders organized around the new venture start-up process. This aspect gives entrepreneurial ecosystems a distinctive resource dynamic. The experimentation-driven approach to business model design gives entrepreneurial ecosystems a distinctive knowledge dynamic. Both of these dynamics, as well as entrepreneurial ecosystem communities themselves, are embedded in regional and national framework conditions that regulate the degree to which entrepreneurial ecosystems are able to realize their economic potential. The four key elements of entrepreneurial ecosystems come togeth-

take advantage of digital technologies and infrastructures in their business models. 
er to provide a supportive environment for digital start-ups.

\section{Entrepreneurial ecosystems as a dis- tinctive type of regional cluster}

Although research has explicitly explored entrepreneurial ecosystems for almost a decade, the research stream remains conceptually fragmented [2, 9]. This is, in part, due to the dominant role practitioners have played in the development of this literature. A number of different definitions have been proposed, many of which emphasizing description rather than theoretical causation, and different definitions reflecting different theoretical perspectives [3, 12-14]. A widely agreed-upon definition of entrepreneurial ecosystems is yet to emerge, and received work has tended to emphasize description and good practice lessons, rather than prediction based on theoretical causation. Regardless of this proliferation, there nevertheless appear to be four common elements that commonly feature in received definitions: (1) regional (rather than national) focus; (2) emphasis on new firm creation; (3) emphasis on multilaterality and interdependencies across ecosystem stakeholders; and (4) emphasis on system-level welfare benefits. Entrepreneurship is typically conceptualized as a regional phenomenon in the sense that the most important regulators of entrepreneurial outcomes are considered to operate at the regional level [15]. Entrepreneurial new firm creation and scale-up is typically considered the primary cluster-level outcome of entrepreneurial ecosystems. Since entrepreneurial ecosystems comprise dynamic multilateral interactions among ecosystem constituents, their definition also involves an element of interdependence and co-evolution among ecosystem participants [16]. Alongside with firm-level outcomes, also broader economic benefits and contribution to economic and societal welfare are occasionally highlighted [1].

In general, many received contributions emphasizing description rather than theoretical causation, there has been little insight into the drivers of the entrepreneurial ecosystem phenomenon, with one recent exception. In their recent contribution, Autio et al. [2] argued that entrepreneurial ecosystems are ultimately driven and enabled by advances in digital technologies and infrastructures and the related process of digitalization, or "the sociotechnical process of applying digitizing techniques to broader social and institutional contexts that render digital technologies infrastructural" [17:749]. Building on that, they proposed that entrepreneurial ecosystems are a distinct type of clusters that specializes in facilitating the start-up and scale-up of new entrepreneurial ventures through the combination of digital affordances (i.e., potentialities to either perform existing functions in novel ways or perform entirely novel functions [18]) with spatial affordances (i.e., proximity-related pecuniary and nonpecuniary externalities extensively explored in the traditional clusters literature [19]). Such digital affordances are important to highlight because they shape the locus of entrepreneurial opportunities, as well as effective practices to pursue such opportunities. What's more, because digital technologies are general-purpose interaction technologies, they create opportunities for a radical re-think of how businesses organize their internal and external interactions for the (co-)creation, delivery, and capture of value - i.e., opportunities for radical business model innovation [20, 21].

The above review has highlighted some causal mechanisms that shape both the entrepreneurial ecosystem phenomenon itself, as well as the entrepreneurial resource allocation dynamics in operation within such ecosystems. A shortcoming in the above review is that most of the above studies have not recognized the fundamental driver of business ecosystems in general and entrepreneurial ecosystems in particular - digitalization [for a recent systematic review that failed to recognize this driver, see: 9]. This failure hampers our ability to understand the phenomenon and may give rise to ineffective and even counter-productive policy recommendations. We next first distil the essence of entrepreneurial ecosystems by articulating the distinctive ventures they facilitate and the four essential structural elements.

\section{Entrepreneurial ecosystems and digital start-ups}

We propose that the entrepreneurial ecosystems specialize in fostering a specific category of new ventures - digital start-ups which leverage digital technologies for disruptive business model innovation. New businesses are a highly heterogeneous category of firms. In terms of technology intensive, they comprise low-technology service businesses (e.g., street food vendors, hairdressers, small-scale traders), low-tomedium tech manufacturing SMEs, and so called high-technology new ventures that specialize in converting scientific advances into new commercialized products and services. Digital startups can operate in many different sectors and are distinguished by the way they harness digital affordances brought about by advances in digital technologies and infrastructures for business model innovation. This gives them four distinctive characteristics. 
First, apart from harnessing a general-purpose technology (i.e., digital affordances), digital start-ups, as a category of new businesses, are industry and technology agnostic: the radical business models they conjure can target customers in virtually any sector [22]. This is because digital technologies and infrastructures are Turing machines (they accept bits as inputs and produce bits as outputs) and can therefore connect to any business resource that features a digital interface. The resulting communicability, associativity, and recombinability of digital resources breaks down various asset specificities associated with physical products and their production, endowing digital start-ups with remarkable flexibility to experiment with product and service combinations and service concepts that permeate traditional industry boundaries [17, 23]. Among other things, this means that instead of operating under a 'production - transaction' logic associated with traditional physical resources, digital start-ups operate under a much more flexible 'interaction - cocreation' logic where, instead of seeking to build, control, and leverage internal resources, they leverage digital technologies and infrastructures to access and recombine valuable digital resources therein [23, 24]. This logic is distinctively different from the logics under which more traditional low- and high-tech startups tend to operate, requiring novel organizing principles and an experimentation-driven approach to business model design, one that emphasizes iterative discovery and creation of novel value co-creation opportunities within the wider ecosystem, instead of attempting to plan and implement preconceived value proposition within an established, asset specific, and therefore inflexible industry architecture $[25,26]$.

Second, from the above it follows that digital startups tend to emphasize service and business model innovation, as opposed to technology-push, product, or process as the key source of opportunities for start-up and scale-up. Business model innovation refers to the design and discovery of novel organizational designs to coordinate and leverage boundary-spanning interactions for value co-creation [27-29]. More specifically, business model innovation is the "implementation of non-trivial changes to at least two business model elements resulting in a business model configuration that is new to the organization's industry and market." [30]. This distinguishes digital start-ups from other types of new ventures, which tend to emphasize technology-push, product, and process innovation as their primary opportunity driver. Digital affordances give rise to horizontalization of value chain and transformation of control nature, leading to high degree of freedom and flexibility in organization of economic activities. Digital technologies are essentially interaction technologies in that they allow a radical re-think of how value co-creating interactions are organized in the economy. They therefore act as a potent driver of business model innovations, by enhancing, extending, and enriching the value co-creating capacity of these interactions [23]. In contrast, low-tech service businesses typically rely on regional idiosyncratic features for differentiation with little consideration of upgrading the organization of existing business activities. Low-to-medium manufacturing SMEs tend to compete with product or process innovations that pursue productivity gains through greater manufacturing efficiency. Finally, conventional high-tech new ventures rely on technology innovations where basic technologies are translated into commercial applications. These three types of new ventures generally create and capture value through conventional business models, where modular product architectures and linear value chains are assumed.

Third, digital start-ups leverage ecosystem architecture as a source of competitive advantage. In line with Porter's value chain and general strategy for competitive advantage, these first three types of start-ups depend heavily on low-cost or differentiation or both to succeed in the market [31]. Their strategies assume a modular vertical value chain structure as the competitive context, in which they seek to position themselves relative to complementary assets [32]. In contrast, digital start-ups operate in a layered modular architecture where digitalization exercises a horizontalizing effect on the organization of value creation activities. Digital start-ups therefore employ platform strategies where value is created through flexible horizontal bundling of digital functionalities and content into the platform. This significantly alleviates the site specificity associated with traditional, asset specific value chain structures. The competitive advantage for digital start-ups arises from their ability to build value co-creating interactions within the platform ecosystem and not so much from cost advantages achievable through classical economies of scale in production [33-36].

Fourth, digital technologies and infrastructures are amenable to supporting exponential scalability. The three types of traditional new ventures in general possess lower scalability relative to digital start-ups because of the need of firm-controlled resources to scale in a linear fashion with the scale of the business operation. Low-tech service firms typically seek to balance the business operation with family and personal life, limiting their scale-up aspiration. Even with scale-up aspirations, low-to-median tech firms such as toy manufactures still need significant resource investment to support scale-up beyond the focal region because of tight coupling between physical goods and value appropriation [37]. Similarly, high-tech firms (other than 
digital), operating in a linear commercialization chain, typically employ licensing model where value appropriation and scalability ultimately remain regulated by physical assets [32]. Because digitalization de-couples form and function and supports the dissociation of the flows of physical goods from associated data, it gives rise to exponential scalability and transforms the nature and patterns of internalization [37, 38]. Uncoupling between form and function and the associated reorganization of value co-creating activities horizontally around digital platforms reduce location and asset specificity, and enable digital start-ups to leverage disintermediation and generativity affordances to flexibly connect with and leverage resource providers and users, accelerating the processes of non-localized discovery and leverage of value co-creation opportunities [2, 17, 39]. Digitally enhanced interactions around digital platforms also lower transaction costs for information acquisition and enhance information transparency, which reduces potential information asymmetry and associated issues such as adverse selection and moral hazard [40]. The net effect of such affordances is to dramatically reduce the cost of scaling the business model.

To summarize, the ability to harness digital affordances makes digital start-ups distinctly different from traditional types of new ventures. This means that digital start-ups operate under a distinctive operational logic, one which draws on distinctive managerial recipes for business model design. Given that the entrepreneurial ecosystem have emerged to facilitate digital start-ups, they therefore require distinctive structural elements, resource dynamics, and management approaches to build and harness an ecosystemlevel shared knowledge and resource base to support this purpose. Our entrepreneurial ecosystem structural model reflects these insights. We argue that entrepreneurial ecosystems constitute a distinctive type of regional cluster, embodied in a regional community of ecosystem stakeholders, and facilitating an experiential knowledge and resource base to support effective organization and scale-up of digital start-ups.

\section{Entrepreneurial ecosystem structural model}

Entrepreneurial ecosystems have emerged in response to opportunities opened by digitalization to facilitate digital start-ups by cultivating generic business process knowledge and providing a munificent resource community. We next build a structural model of entrepreneurial ecosystems.

\subsection{Ecosystem community}

Entrepreneurial ecosystems are regional communities of hierarchically independent stakeholders who participate in and contribute to the entrepreneurial dynamic in the region. A community is a group of network constituents that are more densely connected internally than with other networks [41]. Constituents of the entrepreneurial ecosystem community include: (1) prospective, new, established, former, and serial entrepreneurs; (2) micro angels and business angels; (3) venture capitalists; (4) specialized service provides (e.g., legal, marketing services); (5) financial institutions such as banks and crowdfunding sites; (6) skilled employees; (7) networking and event organisers; (8) accelerator and co-working space teams; (9) trainers and start-up advisors; (10) government agencies; (11) established businesses; (12) mentors. Embedded within this community are both the knowledge dynamic of the ecosystem, as well as the specialized resources that support. For the ecosystem knowledge creation and spill-over processes to operate well, there needs to be a shared culture that encourages business model experimentation, collaboration and knowledge sharing. Entrepreneurial ecosystems are conducive to engendering such a culture because of the horizontalizing effect of digitalization on industrial value chains [2]. Traditional clusters composed of regional thickets of related value chain tend to exhibit a pattern of horizontal competition within the cluster (businesses in the same stage of the value chain are potential substitutes) and vertical networking (with complements in successive stages of the value chain). In contrast, start-ups in entrepreneurial ecosystems are networked horizontally, as they leverage digital platforms and the resource interaction - value cocreation logic to compete against incumbents located outside the cluster. As the start-ups each typically point to their own market opportunities with unique value offerings, and each competes with the same means (i.e., business model innovation), they have a natural incentive to collaborate and share their experiences from their business model experiments.

For the knowledge dynamic to operate well, it requires support and input from a wide range of ecosystem constituents and a close-knit sharing culture. Accordingly, we propose two constituent dimensions of the entrepreneurial ecosystem community: Community Richness and Community Cohesion. By Community Richness, we refer to the breadth and quality of the different ecosystem stakeholders. What distinguishs richness from other measurement indicators such as density proposed by Stangler and Bell-Masterson [42] is the emphasis not only on quantity but also on quality and diversity. Generally speaking, the ecosystem community 
consists of a broad range of stakeholders (our list of 12 examples is not exhaustive) who connect with one another in various ways. Central agents in this community are entrepreneurs, who include prospective, new, established, former, and serial entrepreneurs. The population of prospective, new, and serial and exited entrepreneurs is defined not only by its quantity, but also its quality in terms of entrepreneurs' human and social capital, entrepreneurial experience, and industry experience. The depth and breadth of such qualities can foster peer learning and support, observations of each other's progress, feedback, and sharing of knowledge spilloverregarding past and current entrepreneurial experiences.

While entrepreneurs are primary acting agents of entrepreneurial ecosystems, the ecosystem community also contains other central actors - notably, those providing specialized resources, specialist services and knowledge support, and access to markets and customer demand. Generally speaking, digital startups need three types of resources for new venture creation and scale-up: finance, human capital, and knowledge. For finance, a well-established and wellfunctioning entrepreneurial ecosystem community includes specialist funding providers, such as business angles, venture capitalists, crowdfunding access, and other financial institutions who have experience in start-up investment. Angel investors and associated networks often emerge from the local population of successful entrepreneurs and other wealthy individuals [9]. For human capital, a vibrant community of digitally skilled workforce enhances the possiblity to create high-qualty digital start-ups. For knowledge, a rich start-up community entails a vibrant start-up mentor community, with experienced mentors advising digital start-ups. These are complemented with specialist service providers such as those providing legal, marketing, consulting, and IT services. Other important services include providers of shared space and associated support, such as network organisers, new venture accelerators, co-working space teams, and specialized trainers and start-up advisors. One key stakeholder who provides all three kinds of resources is the established business community which may serve as customers, resource providers, collaborators, and potential exit opportunitiesstart-up. However, different from the hub-and-spoke industrial district where vertically integrated firms are surrounded by small suppliers [43], established firms in digitally enhanced entrepreneurial ecosystems facilitate digital start-ups through distinct collaboration vehicles such as corporate accelerators. Finally, active engagement and facilitation by government agencies is essential to provide necessary and effective policy support for digital start-ups [16].

As these stakeholders are hierarchically independent, specific mechanims are needed to bind the community together and enable it to function. This we call Community Cohesion. Although not all (usually not even most) ecosystem constituents know one another, and some may not even be actively aware that they are part of the community, a close-knit community structure the entrepreneurial ecosystem will enable and facilitate a vibrant knowledge and resource dynamic and drive both venture-level and ecosystemlevel advantages. At the firm level, these manifest themselves as well-resourced, innovative, robust, and scalable business models. At the ecosystem level, these manifest themselves as superior cluster-level knowledge base and associated ecosystem services [2, 44]. A cohesive ecosystem community is characterized by closely connected ecosystem constituents, presence of high-visibility individuals and success cases, a shared community identity, recognition of contributions made towards the community, and an enlightened self-interest that recognizes that by helping others one can also ultimately help him- or herself.

We identify three elements that enhance ecosystem community cohesion: community culture, community identification, and manifestations of success. First, a shared culture and social norms that encourage collaboration and discourage opportunism will encourage both the self-selection of individuals into entrepreneurship (i.e., entrepreneurial stand-up), and also, a healthy knowledge dynamic within the ecosystem community [45]. Silicon Valley's preeminence as a globally leading entrepreneurial ecosystem has been attributed largely to its open and collaborate culture [46]. An important element of an open and collaborative culture involves the recognition that failed business model experiments can be a valuable source of entrepreneurial learning, not only for the focal entrepreneurial team, but also, for the ecosystem community at large, as it generates experience-based insight regarding 'what works' in terms of business model recipes. Such learning is boosted by the reduced cost of entrepreneurial experimentation enabled by digitalization [47, 48]. Evidence shows that ideas and knowledge generated by failure of new ventures tend to become important parts of successful products or services in success cases [49]. There is also evidence that an entrepreneurial culture that encourages ecosystem constituents to contribute their time, knowledge, and experience has been key to successful entrepreneurial ecosystems in Boulder and Waterloo [5, 13].

Second, a strong identification of the stakeholders with the ecosystem community is important for 
effective functioning of the ecosystem. Community identification measures the strength of individual-level identification within a start-up community and it is strengthened by supporting programs such as networking events [50]. According to the literature on organizational communities and networks, community identification emerges gradually through informal interactions [51]. Frequent interactions follow, enabling community members to form an understanding of the role played by different members, as well as their own role within the community, enabling them to form insight how they contribute to the community [52]. A strong community identification promotes knowledge exchanges and spill-overs, enhances collective sensemaking, and reduces search and transaction costs [50]. The more strongly the individual identifies with the ecosystem community, the more deeply they will be embedded within that community. Community awareness and identification is strengthened by networking events, which serve to attract potential ecosystem participants. Summarizing, community identification is a crucial contributor to community cohesion; it facilitates mutual learning among digital start-ups and entrepreneurs; and it can be enhanced by supporting activities and organizations.

Third, visible success cases contribute to community cohesion by providing compelling evidence that the ecosystem works and is able to generate benefits for its constituents. The critical role success cases play in entrepreneruial ecosystems has been emphasized by Isenberg in his "law of small numbers" effect [6]. This notion suggests that even a single success case can have a wide impact because it can attract and inspire current and prospective members of the ecosystem community. Success cases and role model entrepreneurs also provide examples of successful entrepreneurial practices for others to emulate. By mentoring others, visible success cases and role model entrepreneurs can also drive and strengthen a sharing culture, thereby contributing to an advantageous knowledge dynamic. Once a given region has become a visible hotbed of succes cases, ambitious entrepreneurs will be attracted to launch digital start-ups in this community.

\subsection{Resource dynamic}

We conceptualise entrepreneurial ecosystems as regional (typically, city-level) concentrations of community stakeholders and generic and specialized resources that support the digital start-up process. The generic and specialized resources are embedded in the entrepreneurial ecosystem community, which facilitates the access of new ventures to these. A range of different kinds of resources are required for optimal digital start-up process, including different types of funding, human capital, and specialized services. In addition, connectivity to the corporate sector provides important demand pull to drive start-up processes. An important element of the resource dynamic is the reinvestment of entrepreneurial resources into new ventures from successful exits.

Like other types of cluster, also entrepreneurial ecosystems attract specialized resources. In the case of entrepreneurial ecosystems, these resources are specialized in and organized around the entrepreneurial stand-up, start-up, and scale-up processes. The concentration of specialized resources within a defined geographical region makes access to these easier and more efficient. In terms of finance, the specialized forms of finance include business angels, venture capital, and crowdfunding. Experienced business angels in the entrepreneurial ecosystem play a key role in new venture creation and growth because they provide not only financial capital but also business skills and access to personal networks [53]. Crowdfunding, itself a response to the lowered cost of entrepreneurial experimentation brought about by digitalization and made possible by the development of digital infrastructures [11], provides an alternative source of funding earlystage projects [54]. Crowdfunding helps connect small-scale funding by private individuals with prospective product and service concepts and is most useful in supporting the stand-up and start-up stages of new venture creation. Venture capital provides an important mechanism for funding the scale-up stage.

The provision of human capital is equally important within the entrepreneurial ecosystem because high-potential individuals (individuals with high human and social capital) are more likely to successfully launch high-impact new ventures. This is arguably the most important resource to fuel the stand-up and startup stages. An important aspect of this dynamic is the cross-regional and cross-border flow of entrepreneurial talent, as the ability to attract entrepreneurial talent from outside the focal region signals that the ecosystem has succeeded in developing resource and knowledge dynamics that add real value to the start-up process.

Large established firms also play a key role in supporting dynamic resource flows within the entrepreneurial ecosystem. The participation of corporate entities in entrepreneurial ecosystems goes beyond normal supplier relationships explored in the traditional cluster literature and extends to the provision of access to corporate resources (e.g., databases, corporate capabilities, and so on) and the operation of corporate accelerators. Resource flows from the corporate sector also involve access to customers and markets, as well as access to business and industry knowledge 
and insights. In the digital age, corporates also benefit from the contribution of digital start-ups for their own innovation ecosystem development, making corporate participation a key bridge between entrepreneurial and innovation ecosystems. Reinvestment of entrepreneurial resources from successful ventures (including funding raised through exits) is also a key element of the entrepreneurial ecosystem resource dynamic [55]. Successful entrepreneurs, who have made their fortunes through trade sales or IPOs, often remain active in the entrepreneurial ecosystem as serial entrepreneurs, mentors, or as angel investors. Such recycling and reinvestment helps make new resources generated by the ecosystem dynamic 'sticky' to the region [43]. Through re-investment as angel investors, VCs, or advisers, successful exited entrepreneurs feed back their wealth and experience to foster more innovative digital start-ups. The existence of serial entrepreneurs in a region also provides added value as a magnate by attracting more entrepreneurs [55].

\subsection{Knowledge dynamic}

Knowledge acts as the key resource within the entrepreneurial ecosystem. According to Autio et al. [2], entrepreneurial ecosystems differ from other cluster types in that the shared knowledge base is not industry or technology specific but is concerned about disruptive business model innovation - i.e., a radical re-think of how businesses can organise for the co-creation, delivery, and capture of value. Such shared architectural knowledge is developed through entrepreneurial experimentation and can be combined with firm-level component knowledge regarding how specific technologies and industries work. Facilitating a shared knowledge base regarding disruptive business model innovation is a key function of entrepreneurial ecosystems.

Knowledge spill-overs are facilitated by geographical proximity and result in geographical clustering of innovation [56] and start-up activity [57-59]. Although digitalization reduces the costs of transferring codified knowledge across geographical spaces, knowledge, particularly in the tacit format, still requires face-toface, frequent and repeated interactions [60]. As illustrated before, the knowledge spill-over patterns of entrepreneurial ecosystems are distinctly different from those in traditional clusters because of the platformcentric organization of value creating activities. Wellfunctioning entrepreneurial ecosystems are characterized by effective knowledge creation and sharing regarding digitally enhanced business model innovation, with active facilitation from supporting structural elements such as accelerators and co-working spaces. Such knowledge spill-overs provide opportunities for shared sense-making of 'what works' in terms of business model experimentation. Weak ecosystems may exhibit mostly ad-hoc spill-overs where learning is mainly based on competitor observation rather than mutual experience exchange. A well-functioning knowledge dynamic will drive the novelty of business models developed by new ventures within the ecosystem.

Similar to the argument of cross-border resource flows, knowledge (the most important resource) inflows and outflows about innovative business models also plays an important role in the entrepreneurial ecosystem knowledge dynamic. While much of the knowledge regarding 'what works' in terms of radical business model innovation will be developed internally, cross-regional and cross-border flows of business model recipes serve to enrich this knowledge base. Particularly in emerging economies, the adoption of business model templates developed elsewhere and the adaptation of these into local contexts can be an important driver of business model innovation, as the cases of Didi Kuaxi and Alibaba illustrate. In this way, knowledge on business model innovation within the entrepreneurial ecosystem can be updated by the innovative elements discovered and adopted from other locations.

\subsection{General framework conditions}

The final element of entrepreneurial ecosystems does not concern entrepreneurial ecosystems themselves, but rather, the policy framework conditions within which they are embedded. Being complex structures consisting of a heterogeneous community of ecosystem stakeholders, entrepreneurial ecosystems need a supportive general and policy framework to thrive. These general framework conditions are shaped by the sophistication of the entrepreneurship policy apparatus (entrepreneurial ecosystem policies requiring distinctively different policy approaches relative to market or structural failure policies), general regulations regarding market entry (digital start-ups regularly challenging industry incumbents), and the digital infrastructure.

Because entrepreneurial ecosystems specialize in fostering digital start-ups that compete with radical business models, they require policy approaches that differ from those addressing traditional entrepreneurial ventures. Different types of new ventures typically require different faciliation approaches. Low-tomedium manufacturing SMEs inhabit traditional industry clusters and seek to enhance productivity through resource pooling, specialization, and reduced transaction and logistics costs. High-technology 
ventures inhabit regional systems of innovation, where close collaborations between industry, academic and government are supported to enable technology commercialization. Because digital start-ups competing with radical business model innovation do not rely on vertical value chain for productivity enhancement or knowledge maturation chain for technology commercialization, a different set of policy approaches is required to foster digital start-ups. An entrepreneurial ecosystems approach is therefore needed where distinct structural elements such as accelerators and co-working spaces are central [2].

Second, as we illustrated previously, digitalization should be well understood and associated policy should coordinated effectively with entrepreneurial ecosystem approach to fully develop and exploit firmand cluster-level potentials. If the importance of digitalisation is not well understood, it is difficult to design effective policy support to satisfy the distinct needs of digital start-ups. Given the widespread changes in the locus of entrepreneurial opportunities in the digital economy and associated practices for new venture cration and scale-up, coordination of digitalization and entrepreneurial ecosystem policies is important to both facilitate the digital transformation of existing ventures and new digital start-ups.

Because digital start-ups typically launch new services that are subject to government regulation, the degree of proactivity among policy makers plays a key role in preparing effective regulatory environment in entrepreneurial ecosystems. Given the newness of the entrepreneurial ecosystem phenomenon and radical nature of digital transformation, we expect to see a transition during which existing regulatory policies are becoming outdated and adjustments are in huge demand for new solutions. Policy change is a 'collective process' where multiple stakeholders are involved to transform institutitons, and transparency and bottom-up consultation is important in policy formulation period to avoid ineffectiveness [61]. Potential area of adjustments may include market entry, fiscal policy, and government procurement. Business model innovations such as sharing economy models and two-sided market models created by digital start-ups are radical in nature, which challenges existing industry structure and inter-firm relationships. Such disruptive effect significantly reduces the usefulness of existing regulatory frameworks and policies based on the pre-digital age. Regulatory bodies need to recognize the special needs of digital start-ups and harness innovative regulatory practices such as regulatory sandbox to accomodate and support experimentation with radical new business models. This could happen, by opening public procurement in selected areas for business model experimentation by new ventures.

Furthermore, sophistication of EE facilitation is based on a clear understanding of the necessity to implement a new 'ecosystem failure' approach rather than the more traditional, 'market failure' or 'system failure' approaches that inform traditional entrepreneurship policies. The 'market failure' and 'system failure' paradigms are based on the assumption static failures that can be observed and understood by an external operator (such as the policy-maker) that resides outside the system itself. This assumption is central for the received, top-down and policy siloed approaches that are commonly used to fix failures thus observed [62]. Such assumptions, however, do not apply to entrepreneurial ecosystems management. Entrepreneurial ecosystem communities are non-hierarchical, which means that no one actually 'owns' the entrepreneurial ecosystem and no one in entrepreneurial ecosystems can have a full picture of how the ecosystem works [16]. In entrepreneurial ecosystems, each stakeholder possesses different goals and assumes specific responsibilities. No one is obligated to ensure effective operation and function of the ecosystem itself. Entrepreneurial ecosystem services are cocreated by multiple stakeholders in one-to-one interactions and materialized through emergent processes. Multipolar, bottom-up coordination is therefore required that does not depend on hierarchical control. Multipolar coordination is enabled through commitment from all stakeholders to shared ecosystem-level goals [63]. Given the absence of centralized hierarchical control, stakeholders are essentially undertaking voluntary actions to produce collective benefits for the ecosystem, operationalized primarily through the ecosystem's shared knowledge base and associated knowledge spill-overs [16]. According to the collective governance literature, collective benefits cannot be obtained through short-term economic incentives because such approaches may lead to the deterioration of common goods motivations [64]. Such common benefits can be motivated through deep stakeholder engagement to stimulate intrinsic commitment with long-term vision. Therefore, bottom-up and engaged manner should be adopted for entrepreneurship design and delivery. Policy makers should act as a facilitator rather than a central planner, and entrepreneurs should lead the entrepreneurial ecosystem [5].

\section{Conclusion}

In conclusion, our paper contributes to the entrepreneurial ecosystem literature by identifying the unique type of new ventures they foster and by proposing the entrepreneurial ecosystem structural model. 
Although the first to identify key elements of entrepreneurial ecosystems and illuminate their digitally enhanced operational logics, our model is not exhaustive. Further research is therefore necessary to explore further the dynamics of entrepreneurial ecosystems. First, future research could try to test the structural model presented here using the combination of qualitative and quantitative methods and in different contexts, notably, in developed, emerging as well as developing economies. Second, future research should explore more in detail the unique facilitating processes and mechanisms enabled by digital affordances. It would be fruitful to explore what structural elements or processes within entrepreneurial ecosystems are still location specific and which are facing the most challenges from digitalization. Third, existing research has focused on the macro level factors that facilitate or inhibit entrepreneurial activities. However, the existence of resources and structural elements does not necessarily mean more participation and entrepreneurial successes. Future research should look more into the micro level dynamics. For example, the heterogeneous practices entrepreneurs and other stakeholders use to participate in the ecosystem development and the types of benefits they reap from the ecosystem.

\section{References}

[1] Ács, Z.J., E. Autio, and L. Szerb, National systems of entrepreneurship: Measurement issues and policy implications. Research Policy, 2014. 43(3): p. 476-494.

[2] Autio, E., et al., Digital affordances, spatial affordances, and the genesis of entrepreneurial ecosystems. Strategic Entrepreneurship Journal, 2018. 12(1): p. 72-95.

[3] Alvedalen, J. and R. Boschma, A critical review of entrepreneurial ecosystems: towards a future research agenda. European Planning Studies, 2017. 25(6): p. 887-903. [4] Isenberg, D., The entrepreneurship ecosystem strategy as a new paradigm for economic policy: principles for cultivating entrepreneurship: The Babson entrepreneurship ecosystem project, in Babson College, Massachusetts. 2011. [5] Feld, B., Startup communities: Building an entrepreneurial ecosystem in your city. 2012, Hoboken, NJ: Wiley.

[6] Isenberg, D.J., How to start an entrepreneurial revolution. Harvard Business Review, 2010. 88(6): p. 40-50.

[7] Reis, E., The lean startup. 2011, New York, NY: Crown Business.

[8] Hochberg, Y.V., Accelerating Entrepreneurs and Ecosystems: The Seed Accelerator Model. Innovation Policy and the Economy, 2016. 16(1): p. 25-51.

[9] Malecki, E.J., Entrepreneurship and entrepreneurial ecosystems. Geography Compass, 2018. 12(3): p. e12359.

[10] Romme, A.G.L., Making a difference: organization as design. Organization Science, 2003. 14(5): p. 558-573.

[11] Ewens, M., R. Nanda, and M. Rhodes-Kropf, Cost of experimentation and the evolution of venture capital. Journal of Financial Economics, 2018. 128(3): p. 422-442.
[12] Stam, E., Entrepreneurial Ecosystems and Regional Policy: A Sympathetic Critique. European Planning Studies, 2015. 23(9): p. 1759-1769.

[13] Spigel, B., The Relational Organization of Entrepreneurial Ecosystems. Entrepreneurship Theory and Practice, 2015. 41(1): p. 49-72.

[14] Cohen, B., Sustainable valley entrepreneurial ecosystems. Business Strategy and the Environment, 2006. 15(1): p. 1-14.

[15] Feldman, M.P., J. Francis, and J. Bercovitz, Creating a cluster while building a firm: Entrepreneurs and the formation of industrial clusters. Regional Studies, 2005. 39(1): p. 129-141.

[16] Autio, E. and J. Levie, Management of entrepreneurial ecosystems, in The Wiley Handbook of Entrepreneurship, G. Ahmetoglu, et al., Editors. 2017, John Wiley \& Sons: Chichester. p. 423-450.

[17] Tilson, D., K. Lyytinen, and C. Sørensen, Research commentary-Digital infrastructures: The missing IS research agenda. Information Systems Research, 2010. 21(4): p. 748-759.

[18] Majchrzak, A. and M. Markus, Technology affordances and constraints theory (of MIS), in Encyclopedia of Management Theory, E. Kessler, Editor. 2013, SAGE Publications: Thousand Oaks, CA. p. 832-836. [19] Marshall, A., Principles of political economy. 1890, New York, NY: Macmillan.

[20] Amit, R. and C. Zott, Crafting business architecture: The antecedents of business model design. Strategic Entrepreneurship Journal, 2015. 9(4): p. 331-350.

[21] Yoo, Y., et al., Organizing for innovation in the digitized world. Organization Science, 2012. 23(5): p. 13981408.

[22] Basu, S. and J. Fernald, Information and communications technology as a general - purpose technology: Evidence from US industry data. German Economic Review, 2007. 8(2): p. 146-173.

[23] Autio, E. and L.D.W. Thomas, Ecosystem value cocreation, in Working papers, I.C.B. School, Editor. 2016: London. p. 28.

[24] Lusch, R.F. and S. Nambisan, Service innovation: A service-dominant logic perspective. MIS Quarterly, 2015. 39(1): p. 155-175.

[25] Jacobides, M.G., T. Knudsen, and M. Augier, Benefiting from innovation: Value creation, value appropriation and the role of industry architectures. Research Policy, 2006. 35(8): p. 1200-1221.

[26] Barrett, M., et al., Service innovation in the digital age: key contributions and future directions. MIS Quarterly, 2015. 39(1): p. 135-154.

[27] Amit, R. and C. Zott, Value creation in e - business. Strategic management journal, 2001. 22(6 - 7): p. 493-520. [28] George, G. and A.J. Bock, The business model in practice and its implications for entrepreneurship research. Entrepreneurship theory and practice, 2011. 35(1): p. 83-111. [29] Osterwalder, A. and Y. Pigneur, Business model generation: a handbook for visionaries, game changers, and challengers. 2010, Hoboken, NJ: Wiley.

[30] Bock, A.J. and G. George, The Business Model Book: Design, build and adapt business ideas that drive business growth. 2017, London, U.K.: Pearson Education Limited. 
[31] Porter, M.E., Competitive strategy: Techniques for analyzing industries and competitors. 1980, New York, NY: Free Press.

[32] Teece, D.J., Profiting from technological innovation: Implications for integration, collaboration, licensing. Research Policy, 1986. 15: p. 285-305.

[33] Frow, P., et al., Value propositions: A service ecosystems perspective. Marketing Theory, 2014. 14(3): p. 327-351.

[34] Archpru Akaka, M., S.L. Vargo, and R.F. Lusch, An exploration of networks in value cocreation: A serviceecosystems view, in Special issue -Toward a better understanding of the role of value in markets and marketing (Review of Marketing Research, Volume 9), S.L. Vargo and R.F. Lusch, Editors. 2012, Emerald Group Publishing Limited. p. 13-50.

[35] Ramaswamy, V., Co-creation of value-towards an expanded paradigm of value creation. Marketing Review St. Gallen, 2009. 26(6): p. 11-17.

[36] Van Alstyne, M.W., G.G. Parker, and S.P. Choudary, Pipelines, platforms, and the new rules of strategy. Harvard Business Review, 2016. 94(4): p. 54-62.

[37] Akaka, M.A., S.L. Vargo, and R.F. Lusch, The complexity of context: A service ecosystems approach for international marketing. Journal of Marketing Research, 2013. 21(4): p. 1-20.

[38] Mograbyan, M. and E. Autio, New Venture Internationalisation in the Digital Age. Academy of Management Proceedings, 2017. 2017(1).

[39] Zittrain, J.L., The generative internet. Harvard Law Review, 2006: p. 1974-2040.

[40] Estrin, S. and S. Khavul. Equity Crowdfunding and the socialization of entrepreneurial finance. in Academy of Management Proceedings. 2016. Briarcliff Manor, NY Academy of Management.

[41] Girvan, M. and M.E. Newman, Community structure in social and biological networks. Proceedings of the national academy of sciences, 2002. 99(12): p. 7821-7826.

[42] Stangler, D. and J. Bell-Masterson, Measuring an entrepreneurial ecosystem. Kauffman Foundation Research Series on City, Metro, and Regional Entrepreneurship, 2015: p. 1-16.

[43] Markusen, A., Sticky places in slippery space: a typology of industrial districts. Economic Geography, 1996. 72(3): p. 293-313.

[44] Tallman, S., et al., Knowledge, clusters, and competitive advantage. Academy of Management Review, 2004. 29(2): p. 258-271.

[45] Sternberg, R., Regional dimensions of entrepreneurship. Foundations and Trends ${ }^{\circledR}$ in Entrepreneurship, 2009. 5(4): p. 211-340.

[46] Saxenian, A., Regional advantage. 1996, Cambridge. U.K.: Harvard University Press.

[47] Boudreau, K., Let a thousand flowers bloom? An early look at large numbers of software app developers and patterns of innovation. Organization Science, 2012. 23(5): p. 1409-1427.

[48] Boudreau, K.J., Amateurs, N.B.o.E. Research, Editor. 2017: Boston, MA.

[49] Holbrook, D., et al., The nature, sources, and consequences of firm differences in the early history of the semiconductor industry. Strategic Management Journal, 2000: p. 1017-1041.

[50] Autio, E., S. Kanninen, and R. Gustafsson, First-and second-order additionality and learning outcomes in collaborative $R \& D$ programs. Research Policy, 2008. 37(1): p. 59-76.

[51] Ring, P.S. and A.H. Van de Ven, Developmental processes of cooperative interorganizational relationships. Academy of management review, 1994. 19(1): p. 90-118.

[52] Brown, J.S. and P. Duguid, Organizational learning and communities-of-practice: Toward a unified view of working, learning, and innovation. Organization Science, 1991. 2(1): p. 40-57.

[53] Politis, D., Business angels and value added: what do we know and where do we go? Venture capital, 2008. 10(2): p. 127-147.

[54] Mollick, E., The dynamics of crowdfunding: An exploratory study. Journal of business venturing, 2014. 29(1): p. 1-16.

[55] Spigel, B. and R. Harrison, Toward a process theory of entrepreneurial ecosystems. Strategic Entrepreneurship Journal, 2018. 12(1): p. 151-168.

[56] Audretsch, D.B. and M.P. Feldman, $R \& D$ spillovers and the geography of innovation and production. The American Economic Review, 1996. 86(3): p. 630-640.

[57] Rocha, H.O. and R. Sternberg, Entrepreneurship: The role of clusters theoretical perspectives and empirical evidence from Germany. Small Business Economics, 2005. 24(3): p. 267-292.

[58] Glaeser, E.L., W.R. Kerr, and G.A. Ponzetto, Clusters of entrepreneurship. Journal of Urban Economics, 2010. 67(1): p. 150-168.

[59] Wennberg, K. and G. Lindqvist, The effect of clusters on the survival and performance of new firms. Small Business Economics, 2010. 34(3): p. 221-241.

[60] Glaeser, E.L., et al., Growth in cities. Journal of Political Economy, 1992. 100(6): p. 1126-1152.

[61] Arshed, N., S. Carter, and C. Mason, The ineffectiveness of entrepreneurship policy: is policy formulation to blame? Small Business Economics, 2014. 43(3): p. 639-659.

[62] Lundström, A. and L.A. Stevenson, Entrepreneurship policy: Theory and practice. 2005, Boston, MA: Springer.

[63] Goswami, K., J.R. Mitchell, and S. Bhagavatula, Accelerator Expertise: Understanding the Intermediary Role of Accelerators in the Development of the Bangalore Entrepreneurial Ecosystem. Strategic Entrepreneurship Journal, 2018. 12(1): p. 117-150.

[64] Vollan, B., Socio-ecological explanations for crowding-out effects from economic field experiments in southern Africa. Ecological Economics, 2008. 67(4): p. 560573. 